\title{
A step-by-step analytical procedure to estimate the in-situ stress state from borehole data
}

\author{
G. Scelsi • M.L. De Bellis • A. Pandolfi • \\ G. Musso - G. Della Vecchia
}

6 Received: date / Accepted: date

\begin{abstract}
Knowledge of the in situ stress state of rock mass is fundamental for engineering, geological and geophysical applications. In situ stress state determination requires in principle the evaluation of the three principal stresses and the related principal directions, but it is widely recognized in the literature that the maximum horizontal stress is the most difficult component to accurately estimate. In the context of borehole methods, this paper proposes a step-by-step analytical procedure to estimate some bounds to the maximum horizontal stress, starting from a geomechanical description of the rock and relying on information generally available in the engineering practice. The procedure is divided in substeps, each one requiring additional information about the mechanical properties of the rock and on the geometrical properties of the failed portion of rock: more information available implies a lower uncertainty
\end{abstract}

Giulia Scelsi

Department of Civil and Environmental Engineering

Politecnico di Milano, Milano, Italy

E-mail: giulia.scelsi@polimi.it

Gabriele Della Vecchia

Department of Civil and Environmental Engineering

Politecnico di Milano, Milano, Italy

E-mail: gabriele.dellavecchia@polimi.it

Anna Pandolfi

Department of Civil and Environmental Engineering

Politecnico di Milano, Milano, Italy

E-mail: anna.pandolfi@polimi.it

Guido Musso

Department of Structural, Geotechnical and Building Engineering

Politecnico di Torino, Torino, Italy

E-mail: guido.musso@polito.it

Maria Laura De Bellis

Department of Innovation

Università del Salento

E-mail: maria.laura.debellis@unisalento.it 
on in situ stress estimate. Furthermore, since the proposed procedure is analytical, it allows a complete and very easy implementation in a spreadsheet. The aim of the work is thus to provide a rigourous but simple analytical tool that can be used in engineering practicte to estimate some bounds to the maximum horizontal in situ stress state. The approach is finally validated by means of both numerical simulations, performed with a sophisticated numerical tool, and experimental field data coming from the literature.

Keywords In situ stress · borehole · breakout failure · tensile failure · rock mechanics $\cdot$ analytical procedure

\section{Introduction}

Knowledge of in situ stress state is fundamental for the solution of many problems not only in the field of civil, mining and petroleum engineering, but also for geological and geophysical applications. For instance, stress concentration around underground openings is significantly affected by the in situ original stress state, and its knowledge is mandatory for any deformation and instability evaluation of tunells and shafts. When dealing with oil and gas applications (e.g. borehole excavations, sand production management and stimulation interventions), the knowledge of the stress state and its variation is required before and during reservoir depletion, as well as to predict the distribution and the propagation of cracks as a consequence of hydraulic fracturing jobs.

In situ stress state evaluation implies the determination of six independent quantities, namely the components of the Cauchy second order tensor with respect to a given coordinate system. However, it is most common in engineering practice to determine the three principal stresses and to identify the related principal directions. The initial stress state of horizontal and homogeneous soil layers, which are commonly originated by deposition, is generally evaluated by assuming that the vertical and the horizontal directions are principal ones: the vertical stress is considered coincident with the overburden, while the horizontal one is evaluated by means of the $K_{0}$ concept (Jaky, 1944, Schmidt, 1966). When the geometric configuration is more complex, numerical simulations of the deposition process are usually performed by increasing the unit weight of the material. When dealing with rock formations at large depths, the problem of identifying the initial stress state is much more complicated, being the result of many processes and mechanisms, involving tectonic, gravity and residual stresses. At a smaller scale, the in situ state of stress is also locally influenced by the presence of cavities and discontinuities. Uncertainties related to the exact geological history, the constitutive laws and the detailed structure of the rock mass imply that no numerical computations can be performed to reliably simulate the whole geological history and thus to estimate the in situ stress field (Zang and Stephansson, 2010). Nowadays, it is widely accepted in the engineering practice that the in situ stress state can be estimated by means of techniques that disturb the rock itself, evaluating the induced mechanical 
response, which in turn depends on the initial stress state itself.

According to Amadei and Stephansson (1997), classical crustal in-situ measurement techniques require either a well bore (e.g. breakout analysis, hydrofrac) or core materials (e.g. overcoring, strain relief). Despite coring methods are widely used techniques for stress measurement in the engineering practice, they suffer of some limitations related to the maximum depth allowed and to the small volume involved. Borehole methods applicability is vice versa limited just by the maximum borehole depth. Zoback et al (2003) evidenced the advantages and the reliability of borehole methods to determine both stress magnitude and orientation in deep wells, highlighting the role of a sound geomechanical model of the subsurface and of wellbore imaging devices, like ultrasonic televiewers and electrical imaging tools, to yield detailed information about wellbore failure.

The classical strategy that is employed to characterize the stress field (see, e.g. Zoback et al, 2003 and Zoback, 2007) is based on the following steps: i) The vertical equilibrium, i.e. integrating density logs, enables the determination of the vertical stress; ii) Wellbore and recent geologic observations as well as earthquake focal mechanisms allow the determination of the principal stresses directions; iii) The analysis of hydraulic fracturing and leak-off tests (see, e.g. Zoback and Healy (1992) and Haimson et al (2009)) permits the estimation of the minimum principal stress; iv) Direct measurements or a cautious estimation from geophysical logs or seismic data are used to determine pore pressure magnitude. Generally, it is assumed that the vertical stress is principal: as a consequence, the two other principal directions lie in the horizontal plane. This assumption is widely accepted for non-active regions from the tectonics point of view, or for regions where the tectonical stress has already relaxed. In fact, according to Bell (2003), the free surfaces of sedimentary basins are generally horizontal, implying that the principal stress directions can be considered vertical and horizontal. From this picture, it is evident that most difficult component to estimate is the maximum horizontal principal stress. Some bounds to the maximum horizontal stress can be provided by the application of the Anderson faulting theory together with Mohr-Coulomb failure. For any given depth of a rock mass, some limiting values of the difference between the maximum and the minimum principal stresses can be argued, relying on the assumption that the stresses in the earth crust cannot exceed the frictional strength of pre-existing faults. Of course, this argument is valid at a broad scale and, locally, exceptions can exist. Furthermore, an estimate of fault friction angle is needed. Applications are shown in Moos and Zoback (1990), Wiprut and Zoback (2000) and Zoback et al (2003). Shear failure data registered on circular well bores, induced by excavation and pressurization processes, provide other bounds to the maximum horizontal principal stress. Such bounds derive from the shear strength of the material. As a matter of fact, when a well bore is drilled, some material is removed form the original rock mass: the exhumed material is no more able to carry the stress, that is 
transferred to rock around the well. This process implies a stress concentration in the rock surrounding the well. According to the linear elasticity theory, this stress redistribution amplifies the difference between the virgin principal stresses and thus the maximum shear stress in the rock mass. The so-called breakout failure is in fact the consequence of the increase in shear stress on the borehole wall due to the excavation-induced increase of the hoop stress around the wall. Breakout failure can also provide information about the principal stress directions: when either the borehole and the principal stress are vertical, the azimuth of breakout failures coincides with the minimum horizontal stress direction. The reliability of breakout data as a tool to estimate the in situ stress state is justified also by the possibility of having multiple determination of stress in single well and by the possibility to check for regional consistency among numerous wells. Breakout failures have been exploited to determine some limiting values of the maximum horizontal principal stress in Leeman (1964), Bell and Gough (1979), Zoback et al (1986). A relevant role in breakout failure analysis is provided by the failure criterion used to describe rock behaviour: Moos and Zoback (1990) provided solutions by considering a Galileo-Rankine criterion for the compressive strength of the rock, characterized by a constant value, while Vernik and Zoback (1992) provided estimates via the Weibols and Cook (1968) strain energy failure criterion. Zoback et al (1985) exploited the elastic Kirsch solution and Mohr-Coulomb failure criterion to highlight the role of breakout shape and inelastic deformation around the borehole, as later evidenced by Barton et al (1988), Aadnoy et al (2013) and Della Vecchia et al (2014). Important information about the magnitude and the orientation of the horizontal maximum principal stress can be also obtained by drilling induced tensile fractures: these fractures form on the wall of the borehole with an azimuth coincident with the direction of the maximum horizontal stress, when one principal stress is locally tensile.

According to this picture, it is evident that the estimate of in situ rock stress state for engineering purposes suffers, as any other geomechanical application, of a relevant problem: due to the complex stress-strain behavior of rocks, sophisticated theoretical and numerical tools are in principle needed to obtain reliable predictions. The applicability of such models is, however, limited by the effort needed in their calibration and in their numerical implementation, which is generally unaffordable for common engineering applications. In order to overcome this seeming insurmountable dichotomy between reliable predictions and applicability for engineering purposes, this paper presents a step-by-step analytical procedure to estimate the in situ maximum horizontal stress exploiting borehole failure data. The procedure is divided in sub-steps, each sub-step implying an increasing degree of detail about the knowledge of the mechanical properties of the materials involved and on the geometrical properties of the failed portions of rocks. Of course, the larger the quantity of information available, the lower the uncertainty on the estimated stress: the bounds identified by the application of the procedure plays the same role of the classical error bars that are often presented in the literature about in-situ 
stress state. It is worth underlying that the procedure is purely analytical: it is thought to be implemented in a simple spreadsheet and no programming or dedicated software are required. In order for the procedure to be analytical, some simplification are necessarily introduced: for example, the role of temperature changes is neglected, as well as the role of possible not axisymmetric distribution of pore pressure near the well. Remarkably, all the parameters required are easy to determine: in the proposed version of the procedure the rock will be characterized in terms of uniaxial strength and friction angle, while the only information needed from the field is the orientation of the faults (if any) and the size of the breakout failure (if any). The procedure has been successfully validated basing on both numerical analyses and case histories from the literature. Numerical analysis has been performed by means of a Finite Element approach, capable of simulating the mechanical behaviour of the rock surrounding the borehole by means of a brittle damage constitutive model for geological media recently proposed in De Bellis et al (2016, 2017). The model in fact proved able to simulate the mechanical behaviour of both sedimentary and crystalline rocks, both in the pre- and the post-peak stages, showing to be particularly suitable for materials characterized by a brittle behavior. The approximation provided by the simplified analytical solution to the results obtained by means of such a sophisticated numerical tool is excellent, at least for breakout opening lower than $90^{\circ}$, proving that the procedure is able to provide reliable results also for non-circular and collapsed boreholes. Appreciable agreement has been also obtained by applying the procedure to in situ experimental data presented in the literature.

\section{Steps involved in the procedure: methodology}

The procedure to estimate the maximum horizontal stress detailed below involves four sub-steps: Step 1 is based on Anderson faulting theory, and just a broad estimate of the friction angle of the faults is required. Step 2 is based on the application of the Kirsch elastic solution for the redistribution of stresses around a borehole in plane strain conditions: depending on the azimuth and the far-field stress state, the maximum and minimum principal stress on the borehole wall coincides with different stress components, i.e. radial, hoop or vertical. Stress distribution around the hole according to the Kirsch solution, together with simple visual information obtained along borehole depth about the orientation of drilling-induced failure, allows a refinement of the bounds of the far field stress obtained in Step 1. It is worth noting that Step 2 does not require any information about strength properties of the material at the borehole scale, being based on an elastic solution. Step 3 takes advantage on both the information about the presence of tensile and breakout failures on borehole wall and the knowledge of rock failure criterion, further reducing the bounds identified in Step 2. Finally, if also the size of the borehole breakout is known, Step 4 will provide a unique value of the maximum horizontal stress. 
In the following, $S_{v}$ represents the total principal vertical virgin stress, $S_{H}$ the total maximum horizontal virgin stress and $S_{h}$ the total minimum horizontal virgin stress. According to the Introduction, $S_{v}$ and $S_{h}$ are assumed to be known in terms of both magnitude and direction. When dealing with the mechanical behaviour of rocks, the stress to be used in the failure criteria are effective stress, indicated as $S_{v}^{\prime}, S_{h}^{\prime}$ and $S_{H}^{\prime}$ for the vertical and the two horizontal stress directions, respectively. The effective stress tensor, in general indicated as $\sigma_{i j}^{\prime}$ is evaluated according to the poroelastic theory proposed by Biot as

$$
\sigma_{i j}^{\prime}=\sigma_{i j}-\alpha p_{w} \delta_{i j}
$$

where $\sigma_{i j}$ is the total Cauchy stress tensor, $p_{w}$ is the pore fluid pressure, $\alpha$ the Biot coefficient and $\delta_{i j}$ is the Kronecker delta. Experimental and theoretical evidences (e.g. Boutéca and Guéguen, 1999) prove that, even for the same material, $\alpha$ is not a constant, but it depends on the phenomenon that has to be modeled. A large amount of experimental evidence related to sedimentary rocks (Vincké et al. (1998), Espinoza et al. (2015), Sulem and Ouffroukh (2006), Han et al. (2018)) shows that reproducing the elastic behaviour usually requires $\alpha$ to be smaller than one, while reproducing failure generally requires $\alpha$ to be equal to one. Since all the following steps deal with failure conditions, in the following, $\alpha=1$ is assumed and the rock is always considered as saturated.

\subsection{Step 1: limits on the stress state from the tectonic regime}

The idea of using the Anderson (1951) faulting theory to estimate some broad limits on the in situ stress state relies on the assumption that brittle fracture evidenced at the laboratory scale appears to be reproduced also in nature by geological structures (Zang and Stephansson, 2010): faults thus result from brittle failure, according to the Mohr-Coulomb failure criterion. Following Anderson, tectonic stress near the Earth crust can be classified into normal, strike-slip and reverse, depending on the relative combination of the principal stresses (Table 1).

\begin{tabular}{lccc}
\hline Regime & $S_{1}$ & $S_{2}$ & $S_{3}$ \\
\hline Normal NF & $S_{v}$ & $S_{H}$ & $S_{h}$ \\
Strike-slip SS & $S_{H}$ & $S_{v}$ & $S_{h}$ \\
Reverse RF & $S_{H}$ & $S_{h}$ & $S_{v}$
\end{tabular}

Table 1 Principal stresses in the different tectonic regimes

At each depth, the Anderson faulting theory defines some relations between the values of stresses, according to the strength criterion of the material. Let us assume that the Mohr-Coulomb failure criterion holds in the form

$$
\sigma_{1}^{\prime}=C+N_{\phi} \sigma_{3}^{\prime}
$$


being $\sigma_{1}^{\prime}$ and $\sigma_{3}^{\prime}$ the maximum and minimum principal effective stress, respectively, $C$ the uniaxial compressive strength and $N_{\phi}$ a parameter dependent on the friction angle $\phi^{\prime}$, i.e. $N_{\phi}=\left(1+\sin \phi^{\prime}\right) /\left(1-\sin \phi^{\prime}\right)$.

For any tectonic regime, a relation between some of the in situ principal stresses can be identified, corresponding to the fulfilment of Equation 1:

- Normal fault (NF) $S_{v}^{\prime}>S_{H}^{\prime}>S_{h}^{\prime}$

$$
\frac{\sigma_{1}^{\prime}}{\sigma_{3}^{\prime}}=\frac{S_{v}^{\prime}}{S_{h}^{\prime}}=\frac{C}{S_{h}^{\prime}}+N_{\phi}
$$

- Strike-slip fault (SS) $S_{H}^{\prime}>S_{v}^{\prime}>S_{h}^{\prime}$

$$
\frac{\sigma_{1}^{\prime}}{\sigma_{3}^{\prime}}=\frac{S_{H}^{\prime}}{S_{h}^{\prime}}=\frac{C}{S_{h}^{\prime}}+N_{\phi}
$$

- Reverse fault (RF) $S_{H}^{\prime}>S_{h}^{\prime}>S_{v}^{\prime}$

$$
\frac{\sigma_{1}^{\prime}}{\sigma_{3}^{\prime}}=\frac{S_{H}^{\prime}}{S_{v}^{\prime}}=\frac{C}{S_{v}^{\prime}}+N_{\phi}
$$

For a given depth (and thus a given overburden stress) and pore pressure, the equations above identify a region in the horizontal stresses plane: the in situ stress state of the material, that cannot support a shear stress greater than the one identified by the failure criterion, must lay inside the region or on its boundaries. For detailed information about this procedure see Zoback et al. [43] and Moos and Zoback [25].

This first step of the procedure needs just a broad estimate of the strength parameters of the material involved: as it has been shown from laboratory studies on a large variety of rock samples and from in situ experiments in different fault regimes, the friction coefficient generally ranges between 0.6 and 1.0 (i.e. $\phi^{\prime}$ between $30^{\circ}$ and $45^{\circ}$ ). In this case just literature data of friction angle for the studied litotypes can be used, being not known a priori if the major role in terms of failure is provided by the faults or by the core material. As for the value of the uniaxial strength, it is worth evidencing that in petroleum engineering applications the role of $C$ in drawing stress polygons is generally neglected.

In the following, each step of the procedure is applied to a well documented case study from the literature, i.e. a 2-km-deep research borehole (Hole-B) drilled in the context of the drilling project investigating the Chelungpu Fault (Taiwan). Information about material properties and in situ stress state can be found in different studies present in the literature (e.g. Wu et al., 2007, Hung et al., 2007, Lin et al., 2009, Haimson et al., 2009); leak-off tests allowed the determination of the variation of the minimum horizontal principal stress $S_{h}$ with depth, while from the interpretation of formation microscanner FMS results breakout widths have been estimated for depths between $940 \mathrm{~m}$ and $1310 \mathrm{~m}$. Figure 1 shows the stress state limits that can be identified for a depth of $1000 \mathrm{~m}$, where the rock mass is characterized by a a far-field minimum 
horizontal principal stress equal to $S_{h}^{\prime}=10.8 \mathrm{MPa}$ and a far-field vertical effective stress $S_{v}^{\prime}=14.7 \mathrm{MPa}: S_{H}^{\prime}$ is limited by a lower bound $S_{H}^{\prime}=S_{h}^{\prime}=10.8$ $\mathrm{MPa}$ and by an upper bound $S_{H}^{\prime}=39.8 \mathrm{MPa}$, corresponding to a stress anisotropy $S_{H}^{\prime} / S_{h}^{\prime}=3.7$ deriving from the limit corresponding to the strikeslip regime. Values of $\phi^{\prime}=35^{\circ}$ and saturated density $\rho_{\text {sat }}=2.5 \mathrm{~g} / \mathrm{cm}^{3}$ have been used, according to Haimson \& Rudnicki (2009) and Wang (2011). Pore pressure has been assumed to be hydrostatic.

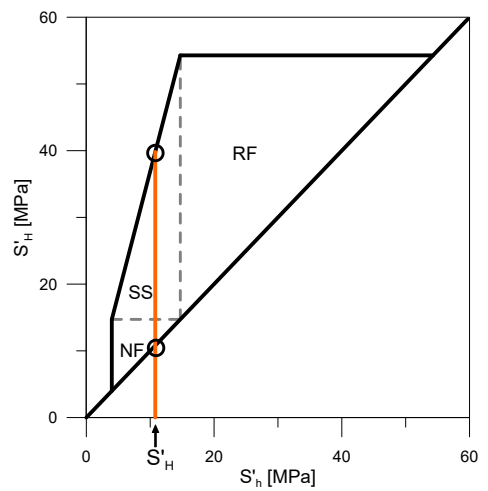

Fig. 1 Admissible stress polygon and limits from tectonic regimes for the Chelungpu fault site.

The estimate of the bounds on the value of the maximum horizontal stress identified at Step 1 can be refined by means of a visual inspection of borehole failure, performed, e.g., by ultrasonic televiewers. It is well known that a circular hole in a isotropic linear elastic material induces a perturbation in the stress field, which can be computed according to the Kirsch solution. In the following, $a$ is the internal radius of the circular hole, subjected to a uniform internal pressure $p_{i}$ ), $r$ is the radial coordinate, i.e. the distance from borehole center that varies between $a$ and $\infty$, and $\theta$, positive counterclockwise, is the angle between the radius considered and the direction of the maximum horizontal stress (see figure 2). Another useful variable is the so-called net pressure $p_{\text {net }}$, defined as the difference between $p_{i}$ and the pressure of the pore fluid, ${ }_{282} p_{w}: p_{\text {net }}=p_{i}-p_{w}$. The Kirsch solution, developed in plain strain conditions, 283 reads (see, e.g. Jaeger [21]): 


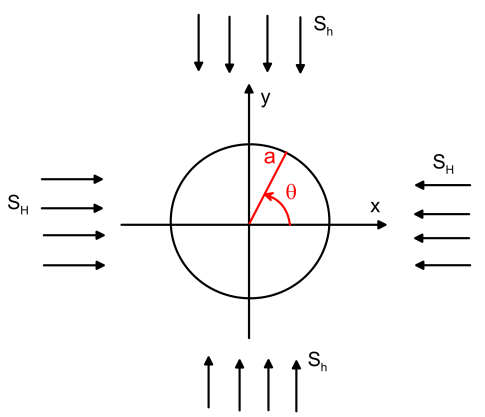

Fig. 2 Radial coordinates for the circular hole

$$
\begin{aligned}
\sigma_{r}^{\prime} & =\frac{1}{2}\left(S_{H}^{\prime}+S_{h}^{\prime}\right)\left[1-\left(\frac{a}{r}\right)^{2}\right]+p_{\text {net }}\left(\frac{a}{r}\right)^{2}+\frac{1}{2}\left(S_{H}^{\prime}-S_{h}^{\prime}\right)\left[1-4\left(\frac{a}{r}\right)^{2}+3\left(\frac{a}{r}\right)^{4}\right] \cos 2 \theta, \\
\sigma_{\theta}^{\prime} & =\frac{1}{2}\left(S_{H}^{\prime}+S_{h}^{\prime}\right)\left[1+\left(\frac{a}{r}\right)^{2}\right]-p_{\text {net }}\left(\frac{a}{r}\right)^{2}-\frac{1}{2}\left(S_{H}^{\prime}-S_{h}^{\prime}\right)\left[1+3\left(\frac{a}{r}\right)^{4}\right] \cos 2 \theta, \\
\tau_{r \theta} & =-\frac{1}{2}\left(S_{H}^{\prime}-S_{h}^{\prime}\right)\left[1+2\left(\frac{a}{r}\right)^{2}-3\left(\frac{a}{r}\right)^{4}\right] \sin 2 \theta,
\end{aligned}
$$

where $\sigma_{\theta}^{\prime}, \sigma_{r}^{\prime}$ and $\tau_{r \theta}$ are the effective hoop, radial and shear stress, respectively and $S_{H}^{\prime}$ and $S_{h}^{\prime}$ are maximum and the minimum horizontal effective far-field stresses.

Under the assumption of drilling operations performed in plane strain conditions in the vertical direction, the principal stresses on borehole wall $(r=a)$ and $\theta=0$ can be expressed, according to the Kirsch solution, as

$$
\begin{aligned}
\sigma_{r}^{\prime} & =p_{\text {net }} \\
\sigma_{\theta}^{\prime} & =3 S_{h}^{\prime}-S_{H}^{\prime}-p_{\text {net }}, \\
\sigma_{z}^{\prime} & =S_{v}^{\prime}+\Delta \sigma_{z}^{\prime}=S_{v}^{\prime}+2 \nu\left(S_{h}^{\prime}-S_{H}^{\prime}\right) .
\end{aligned}
$$

In accordance with the elastic solution introduced, the increment $\Delta \sigma_{z}^{\prime}$ due to borehole excavation follows from the assumption of null vertical strain increment $\left(\Delta \varepsilon_{z}=0\right)$. The increments of radial and hoop stress can finally be calculated as $\Delta \sigma_{r}^{\prime}=p_{\text {net }}-S_{h}^{\prime}$ and $\Delta \sigma_{\theta}^{\prime}=\sigma_{\theta}^{\prime}-S_{H}^{\prime}=2^{\prime} S_{H}-S_{h}^{\prime}-p_{\text {net }}$, so that $\Delta \sigma_{z}^{\prime}=2 \nu\left(S_{H}^{\prime}-S_{h}^{\prime}\right)$ (being $\nu$ the Poisson coefficient of the rock).

If the stress components are divided by the minimum effective far-field horizontal stress $S_{h}^{\prime}$, the role of the far-field stress anisotropy ratio $S_{H}^{\prime} / S_{h}^{\prime}$ is highlighted: 


$$
\begin{aligned}
& \frac{\sigma_{r}^{\prime}}{S_{h}^{\prime}}=\frac{p_{n e t}}{S_{h}^{\prime}} \\
& \frac{\sigma_{\theta}^{\prime}}{S_{h}^{\prime}}=3-\frac{S_{H}^{\prime}}{S_{h}^{\prime}}-\frac{p_{n e t}}{S_{h}^{\prime}} \\
& \frac{\sigma_{z}^{\prime}}{S_{h}^{\prime}}=\frac{S_{v}^{\prime}}{S_{h}^{\prime}}+2 \nu\left(1-\frac{S_{H}^{\prime}}{S_{h}^{\prime}}\right) .
\end{aligned}
$$

Equations (8) represent three lines in the $\sigma^{\prime} / S_{h}^{\prime}$ vs. $S_{H}^{\prime} / S_{h}^{\prime}$ plane, that can be easily drawn when the relevant information about $S_{v}^{\prime}, S_{h}^{\prime}$ and $p_{\text {net }}$ are known: for example, plotting the three lines allows the visualization of the maximum, the intermediate and the minimum principal stresses on borehole wall for $\theta=0$, i.e. when tensile failure is anticipated.

Figure 3(a) shows an example of the evolution of the stress state in $\theta=0$ as a function of the horizontal anisotropy ratio for $S_{v}^{\prime}=14.7 \mathrm{MPa}$ and $p_{n e t}=$ $0 \mathrm{MPa}$. The maximum stress anisotropy considered in the example is the one identified in Step 1, i.e. $S_{H}^{\prime} / S_{h}^{\prime} \leq 3.7$ (see section 2.1). It is evident that for low values of $S_{H}^{\prime} / S_{h}^{\prime}$, the minimum principal stress is the radial one, while for high values of $S_{H}^{\prime} / S_{h}^{\prime}$ the hoop stress becomes the minimum one. If a visual information about tensile failure is provided, it is possible to determine what is the direction of the minimum principal stress: vertical fractures are generally obtained if the hoop stress is minimum, horizontal fractures if the vertical stress is minimum, concentric fractures if the radial stress is minimum (see, e.g Zang and Stefansonn, 2010). Once the minimum principal stress is identified, the relevant zone according to Equation (8) can be identified, and thus a further limitation in stress anisotropy is obtained. According to the example, in the presence of vertical fractures $\sigma_{\theta}^{\prime}$ has to be the minimum principal stress, and so $3 \leq S_{H}^{\prime} / S_{h}^{\prime} \leq 3.7$; if concentric fractures are detected, $\sigma_{r}^{\prime}$ is the minimum principal stress, so that $1 \leq S_{H}^{\prime} / S_{h}^{\prime} \leq 3$. The limiting anisotropies separating the different tensile failure orientation can be plotted in the stress polygon, as shown in Figure 4, where the line $S_{H}^{\prime}=3 \cdot S_{h}^{\prime}$ divides vertical and concentric fractures.

The same logical path can be applied on the borehole wall in $\theta=\pi / 2$, when shear failure is anticipated: also in this case the failure pattern is dependent on which components are the maximum and the minimum ones. In this case the principal effective stresses on borehole wall $(r=a)$ reads:

$$
\begin{aligned}
\sigma_{r}^{\prime} & =p_{\text {net }} \\
\sigma_{\theta}^{\prime} & =3 S_{H}^{\prime}-S_{h}^{\prime}-p_{\text {net }} \\
\sigma_{z}^{\prime} & =S_{v}^{\prime}+2 \nu\left(S_{H}^{\prime}-S_{h}^{\prime}\right),
\end{aligned}
$$




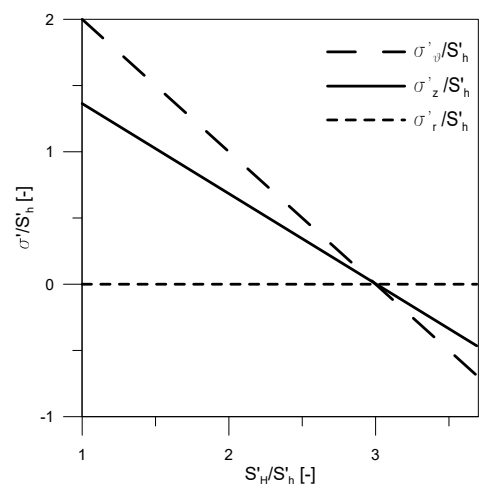

(a) $\theta=0$

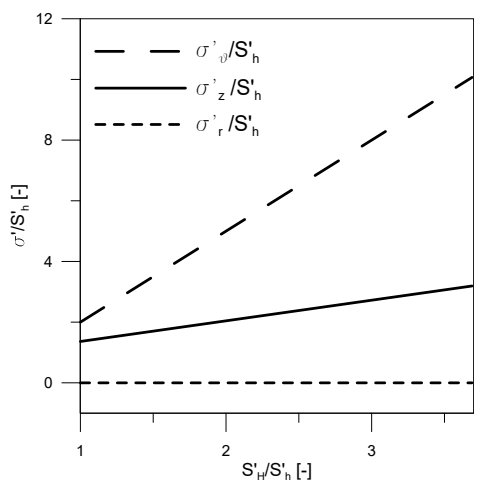

(b) $\theta=\pi / 2$

Fig. 3 Relation between normalized principal components as a function of horizontal stress anisotropy $S_{H}^{\prime} / S_{h}^{\prime}\left(S_{v}^{\prime}=14.7 \mathrm{MPa}, \nu=0.34, p_{\text {net }}=0\right)$.

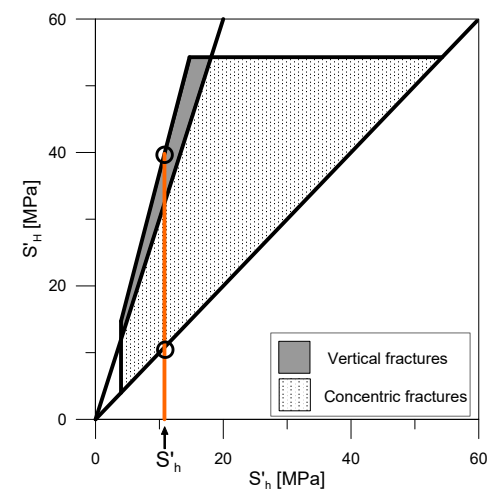

Fig. 4 Identification of the regions where the different tensile failure orientations can potentially take place.

and in non dimensional form

$$
\begin{aligned}
\frac{\sigma_{r}^{\prime}}{S_{h}^{\prime}} & =\frac{p_{n e t}}{S_{h}^{\prime}} \\
\frac{\sigma_{\theta}^{\prime}}{S_{h}^{\prime}} & =3 \frac{S_{H}^{\prime}}{S_{h}^{\prime}}-1-\frac{p_{n e t}}{S_{h}^{\prime}} \\
\frac{\sigma_{z}^{\prime}}{S_{h}^{\prime}} & =\frac{S_{v}^{\prime}}{S_{h}^{\prime}}+2 \nu\left(\frac{S_{H}^{\prime}}{S_{h}^{\prime}}-1\right) .
\end{aligned}
$$

Figure $3(\mathrm{~b})$ shows the evolution of the stress components in $\theta=\pi / 2$ as a function of the horizontal anisotropy ratio and it clearly illustrates that in this specific case for all the admissible anisotropy ratios the radial effective 1 stress is always the minimum principal stress and the hoop stress is always the maximum principal stress $\left(\sigma_{r}^{\prime}<\sigma_{z}^{\prime}<\sigma_{\theta}^{\prime}\right)$. In this specific case, such an information cannot provide any further refinement of $S_{H}^{\prime}$ bounds, because just 
a type of breakout failure is predicted. If viceversa also the lines predicted by (10) would cross themselves, then the same logic of Figure 3(a) can be followed: depending on failure pattern in the breakout zone, the relevant region in term of stress anisotropy could be identified.

\subsection{Step 3: limits on the stress state from rock failure criterion}

According to Equation 6, under the assumption of plane strain conditions during drilling operations, the complete effective state of stress can be written on borehole wall $(r=a)$, allowing to determine, once the strength parameters of the materials are known, if failure conditions are met. According to the literature, the evolution of the effective hoop stress on the borehole wall can be considered as a proxy to determine which zones of the borehole can be subjected to shear failure and which ones to tensile failures. Writing $\sigma_{\theta}^{\prime}$ as a function of $\theta$ in $r=a$ leads to the expression

$$
\sigma_{\theta}^{\prime}(a, \theta)=\left(S_{H}^{\prime}+S_{h}^{\prime}\right)-p_{\text {net }}-2\left(S_{H}^{\prime}-S_{h}^{\prime}\right) \cos 2 \theta,
$$

that shows that the minimum value $3 S_{h}^{\prime}-S_{H}^{\prime}-p_{\text {net }}$ is achieved for $\theta=0$ or $\theta=\pi$, while the maximum one, $3 S_{H}^{\prime}-S_{h}^{\prime}-p_{\text {net }}$, for $\theta=\pi / 2$, or $\theta=3 / 2 \pi$.

If the elastic and strength parameters of the material, as well as the values of $S_{v}, S_{h}, p_{\text {net }}$ and $p_{w}$, are known from previous determinations, it is possible to obtain some bounds for $S_{H}$ depending on the occurrence of compression or tensile failure at the borehole wall.

\subsubsection{Using breakout failure to estimate maximum horizontal stress $S_{H}$ bounds}

When a breakout failure occurs, Step 3 of the procedure allows the determination of a lower bound for the maximum horizontal stress $S_{H}^{\prime m i n}$. This step relies on the assumption that, as soon as breakout failure starts to develop, it involves just a single point of the borehole wall, rather than a finite volume of rock. Breakout failure generally starts at an azimuth $\theta=\pi / 2$, i.e. where $\sigma_{\theta}^{\prime}$ is locally the maximum principal stress. Equation (10) shows the dependence of the principal stresses on the the far-field (virgin) stresses in $\theta=\pi / 2$.

Because both the principal effective stresses on the borehole wall $\sigma_{\theta}^{\prime}$ and $\sigma_{z}^{\prime}$ depend on the only unknown of the problem $S_{H}^{\prime}$, from the mathematical point of view the problem reduces to finding $S_{H}^{\prime}$ such that

$$
f_{C}\left(\sigma_{z}^{\prime}\left(S_{H}^{\prime}\right), \sigma_{r}^{\prime}, \sigma_{\theta}^{\prime}\left(S_{H}^{\prime}\right)\right)=f_{C}\left(S_{H}^{\prime}\right)=0,
$$

where $f_{C}\left(\sigma_{i j}^{\prime}\right)=0$ is a suitable shear failure criterion of the material. The methodology is intended to work for any failure criterion, and analytical solutions can be found for several failure criteria, e.g. Mohr-Coulomb, Hoek-Brown and Mogi-Coulomb (Hashemi et al, 2014, 2015). For the sake of simplicity, in 
the following just the Mohr-Coulomb (MC) criterion will be considered, being its parameters the easiest to determine.

The Mohr-Coulomb failure criterion can be expressed in terms of maximum and minimum principal effective stresses ( $\sigma_{1}^{\prime}$ and $\sigma_{3}^{\prime}$ respectively) as:

$$
\sigma_{1}^{\prime}=C+N_{\phi} \sigma_{3}^{\prime} .
$$

where $C$ is the uniaxial compression strength and $N_{\phi}=\frac{1+\sin \phi^{\prime}}{1-\sin \phi^{\prime}}$, being $\phi^{\prime}$ the internal friction angle. For $\theta=\pi / 2$, where breakout failure are anticipated, the maximum principal stress is generally $\sigma_{\theta}^{\prime}$. For the minimum principal stress two cases are possible, i.e. $\sigma_{3}^{\prime}=\sigma_{r}^{\prime}$ and $\sigma_{3}^{\prime}=\sigma_{z}^{\prime}$ :

- If the minimum principal stress is $\sigma_{r}^{\prime}$, the value of $S_{H}^{\prime}$ corresponding to failure (for given $S_{v}^{\prime}$ and $S_{h}^{\prime}$ ) is

$$
S_{H}^{\prime M C}=\frac{1}{3}\left[S_{h}^{\prime}+\left(1+N_{\phi}\right) p_{\text {net }}+C\right] \text { if } \sigma_{3}^{\prime}=\sigma_{r}^{\prime},
$$

- If the minimum principal stress is $\sigma_{z}^{\prime}$, it follows that

$$
S_{H}^{\prime M C}=\frac{C+N_{\phi} S_{v}^{\prime}+S_{h}^{\prime}\left(1-2 \nu N_{\phi}\right)+p_{\text {net }}}{3-2 \nu N_{\phi}} \text { if } \sigma_{3}^{\prime}=\sigma_{z}^{\prime} .
$$

If breakout failure occurs, $S_{H}^{\prime}{ }^{M C}$ has to be considered as a lower bound for $S_{H}^{\prime}$, because in order to have failure, a value of $S_{H}^{\prime} \geq S_{H}^{\prime}{ }^{M C}$ is needed. Viceversa, if breakout failure does not occur, then $S_{H}^{\prime}{ }^{M C}$ has to be considered an upper bound for $S_{H}^{\prime}$.

Figure 5(a) shows the line expressed by equation 14 taking $C=79.5 \mathrm{MPa}$ and $\phi^{\prime}=35^{\circ}$, representing a bound for the maximum horizontal stress $S_{H}^{\prime}$, thus identifying two possible domains for $S_{H}^{\prime}$ according to the detection of breakout failures. Due to the presence of shear failures in the considered borehole section, it can be stated that $S_{H}^{\prime}$ has to be greater than $S_{H}^{\prime}>30.1 \mathrm{MPa}$ (therefore $S_{H}^{\prime} / S_{h}^{\prime}>2.8$ ) for the specified $S_{h}^{\prime}$ value. Step 3 of the procedure, accounting for breakout failure, is shown in Figure 5(b): the admissible stress state has to fall between the limits deriving from Anderson faulting theory (Step 1) and from the detection of breakout.

\subsubsection{Using tensile failure to estimate maximum horizontal stress $S_{H}$ bounds}

Also when a tensile failure occurs, Step 3 of the procedure allows the determination of a lower bound for the maximum horizontal stress $S_{H}^{\prime m i n}$, which is in general different from the one estimated for breakout failure. Also for tensile failure, the step relies on the assumption that, as soon as failure starts to develop, it involves just a single point of the borehole wall, rather than a finite volume of rock. Tensile failure in general starts at an azimuth $\theta=0$, i.e. where $\sigma_{\theta}^{\prime}$ is locally the minimum principal stress. Equation (8) shows the dependence of the principal stresses on the the far-field (virgin) stresses in $\theta=0$. 


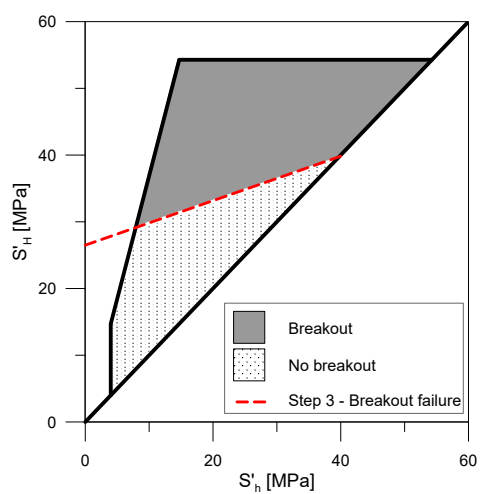

(a)

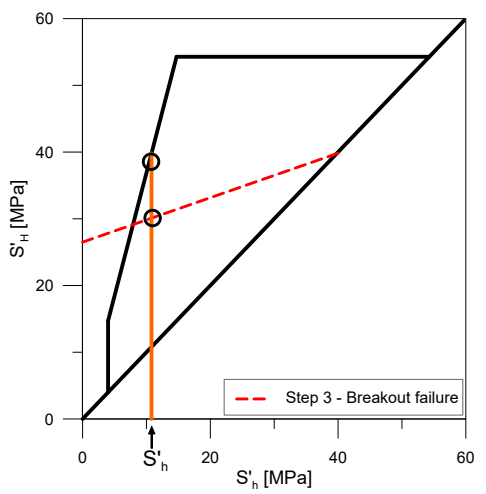

(b)

Fig. 5 Stress polygon with the dashed red line identifying the lower bounds for $S_{H}^{\prime}$ in order to have breakout failures according to the Mohr-Coulomb failure criterion.

Also in this case the principal effective stresses $\sigma_{\theta}^{\prime}$ and $\sigma_{z}^{\prime}$ depends on the unknown $S_{H}^{\prime}$, that can be found by imposing

$$
f_{T}\left(\sigma_{z}^{\prime}\left(S_{H}^{\prime}\right), \sigma_{r}^{\prime}, \sigma_{\theta}^{\prime}\left(S_{H}^{\prime}\right)\right)=f_{T}\left(S_{H}^{\prime}\right)=0,
$$

where $f_{T}\left(\sigma_{i j}^{\prime}\right)=0$ is the chosen tensile failure criterion for the rock. Also in this case, the methodology is intended to work for any failure criterion. For the sake of simplicity, in the following part just the Galileo-Rankine $(\mathrm{G})$ criterion will be considered, because it requires just one parameter to determine, i.e the tensile strength $S_{T}$.

The Galileo failure criterion depends only on the minimum principal stress $\left(\sigma_{3}^{\prime}\right)$, so that

$$
\sigma_{3}^{\prime}=S_{T} .
$$

For $\theta=0$, where tensile failures are anticipated, the minimum principal stress is $\sigma_{\theta}^{\prime}$. The value of $S_{H}^{\prime}$ corresponding to failure (for given $S_{h}^{\prime}$ ) is

$$
S_{H}^{\prime}{ }^{G}=3 S_{h}^{\prime}-S_{T}-p_{\text {net }} .
$$

In the case that tensile failure occurs, $S_{H}^{\prime}{ }^{G}$ has to be considered as a lower bound for $S_{H}^{\prime}$, i.e. in order to have failure, a value of $S_{H}^{\prime} \geq S_{H}^{\prime G}$ is needed. Viceversa, if tensile failure does not occur, then ${S_{H}^{\prime}}^{G}$ has to be considered an upper bound for $S_{H}^{\prime}$.

Figure 6(a) shows the line expressed by equation 18 , representing an upper bound for the maximum horizontal stress $S_{H}^{\prime}$, since no tensile fractures have been registered in the section taken as example. Two possible domains for $S_{H}^{\prime}$ are identified according to the detection of tensile failures. A value $S_{T}=$ 5.4 MPa, as reported by Haimson \& Rudnicki (2009), has been considered. Combining this information with that derived in 2.3.1, it can be stated that $S_{H}^{\prime}$ ranges between $30.1 \mathrm{MPa}$ (Fig. $6(\mathrm{~b})$ ) and $37.8 \mathrm{MPa}$ (corresponding to $2.8<$ $\left.S_{H}^{\prime} / S_{h}^{\prime}<3.5\right)$ for the specified $S_{h}^{\prime}$ value. 


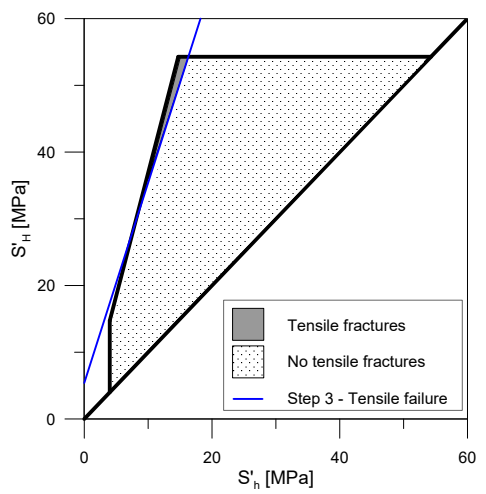

(a)

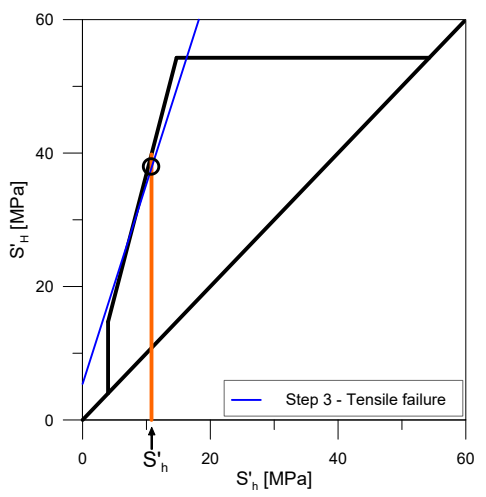

(b)

Fig. 6 Stress polygon with the blue dashed line identifying the lower bounds for $S_{H}^{\prime}$ in order to have tensile failures according to the Galileo strength criterion.

\subsection{Step 4: accounting for breakout size}

In order to further reduce the uncertainties related to the determination of $S_{H}^{\prime}$, an analytical solution was provided in Della Vecchia et al (2014), by exploiting also the information about the breakout width. Step 4 thus not only need the knowledge of the parameters characterizing the rock failure criterion, but also detailed outputs from dipmeters or borehole televiewers during well loggings. According to Barton et al. (1998), the angle $\alpha_{b}$ subtending the breakout zone from the center of the hole is introduced. The same information in terms of azimuth is given by $\theta_{b}\left(\theta_{b}=\pi / 2-\alpha_{b} / 2\right)$, which measures the angle between the radius passing from the extremity of the breakout zone and the direction of the $S_{H}$. The proposal of Della Vecchia et al (2014) is based on the assumption that the experimental breakout size measured at the borehole wall coincides with the size of the yield zone that would originate in the same conditions if the material is elastic perfectly plastic. Accordingly, the principal effective stresses on borehole wall in $\theta=\theta_{b}$ can be expressed as

$$
\begin{aligned}
\sigma_{\theta}^{\prime} & =S_{H}^{\prime}+S_{h}^{\prime}-p_{\text {net }}-2\left(S_{H}^{\prime}-S_{h}^{\prime}\right) \cos 2 \theta_{b} \\
\sigma_{z}^{\prime} & =S_{v}^{\prime}+\Delta \sigma_{z}^{\prime} \\
\sigma_{r}^{\prime} & =p_{\text {net }}
\end{aligned}
$$

Also in this case, the increment $\Delta \sigma_{z}^{\prime}$ has been estimated assuming plane strain conditions in the vertical direction, i.e. $\Delta \varepsilon_{z}=0$. Assuming that in $\theta=\theta_{b}$ both the elastic solution $((6))$, and the Mohr-Coulomb yield condition $((13))$ are fulfilled, i.e. the material is prone to yield, the effective stress distribution obtained depends both on the size of the yielded zone and on the chosen yield function. As for the elastic case, in $\theta=\theta_{b}$ the hoop stress $\sigma_{\theta}^{\prime}$ is the maximum principal stress, while the minimum one is not know a priori: also in this case 


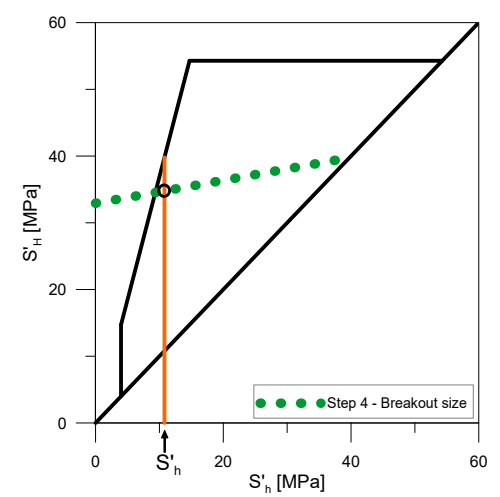

Fig. 7 Stress polygon with green dotted line identifying the value of $S_{H}^{\prime}$ at $\theta_{b}=68^{\circ}$ (eq. 20).

two possibilities must be taken into account. If the minimum principal stress is $\sigma_{r}^{\prime}$, then

$$
S_{H}^{\prime}=\frac{C-S_{h}^{\prime}\left(1+2 \cos 2 \theta_{b}\right)+\left(1+N_{\phi}\right) p_{\mathrm{net}}}{1-2 \cos 2 \theta_{b}}, \quad \sigma_{3}^{\prime}=\sigma_{r}^{\prime} .
$$

If the minimum principal stress is $\sigma_{z}^{\prime}$, then:

$$
S_{H}^{\prime}=\frac{C+N_{\phi} S_{v}^{\prime}+S_{h}^{\prime}\left[-1-2 \cos 2 \theta_{b}\left(1-\nu N_{\phi}\right)\right]+p_{\text {net }}}{1+2 \cos 2 \theta_{b}\left(\nu N_{\phi}-1\right)}, \quad \sigma_{3}^{\prime}=\sigma_{z}^{\prime} .
$$

If the breakout size is known, a unique value of the maximum horizontal stress $S_{H}$ can be determined. In the example, $\sigma_{r}^{\prime}$ is taken as the minimum principal stress, assuming the principal components in $\theta=\theta_{b}$ to have the same relations as those in $\theta=\pi / 2$. Equation 20, plotted in Figure 7, identifies a single value of $S_{H}^{\prime}$ for each minimum horizontal stress $S_{h}^{\prime}$ : it is evident that the stress states with a known breakout width are larger than the stresses deriving only from breakout failure starting at $\theta=\pi / 2$. For the $S_{h}^{\prime}$ value at $1000 \mathrm{~m}$ depth, equal to $10.8 \mathrm{MPa}$, the maximum horizontal stress $S_{H}^{\prime}$ takes the value of $34.8 \mathrm{MPa}$ (corresponding to $S_{H}^{\prime} / S_{h}^{\prime}=3.2$ ); this value falls between the limits obtained in Step 3.

Table 2 summarises the bounds for $S_{H}^{\prime}$ obtained using the proposed approach for the Chelungpu site at $1000 \mathrm{~m}$. It is evident that the greater the detail of the analysis and the larger the information available, the lower the uncertainty of $S_{H}^{\prime}$ estimate.

\section{Numerical validation of the procedure}

The procedure proposed is characterized by a continuous refinement of the bounds in which the real value of $S_{H}^{\prime}$ should lie. If information on the mechanical properties of the material and the size of the breakout failures is 


\begin{tabular}{cccl}
\hline Step & $S_{H}^{\prime}{ }^{\min }[\mathrm{MPa}]$ & $S_{H}^{\prime}{ }^{\max }[\mathrm{MPa}]$ & Information needed \\
\hline 1 & 10.8 & 39.8 & Broad estimate of $\phi^{\prime}$ \\
2 & Data not available & Data not available & Visual information of failures \\
3 & 30.1 & 37.8 & $C, \phi^{\prime}, S_{T}$ \\
4 & 34.8 & 34.8 & $C, \phi^{\prime}$, breakout width \\
\hline
\end{tabular}

Table 2 Bounds for $S_{H}^{\prime}$ for each step using the proposed procedure for Chelungpu-Hole B at $1000 \mathrm{~m}$

available, then Step 4 allows the determination of a unique value of $S_{H}^{\prime}$. As a consequence, a relevant issue is provided by the reliability of Equations 20 and 21. In Della Vecchia et al. (2014), FEM simulations were performed to check if the analytical equations proposed were consistent with the mechanical behaviour of an elastic-perfectly plastic material at the borehole scale. However, rocks hardly behave as perfectly plastic materials, often showing a brittle stress-strain response under stress paths that lead the material to failure: stress redistribution due to material failure and the consequent induced anisotropy cannot be accounted for when perfect plasticity is assumed. In order to validate step 4 of the procedure with reference to issues related to the loss of circularity of the hole, the outcome of equations 20 and 21 has been compared with the results of numerical simulations performed by considering the complex stress-strain behaviour of the rock, including the possibility of brittle failure. In particular, borehole excavation has been simulated via the Finite Element Method, assuming the stress-strain relation to be described by the brittle-damage constitutive model presented in De Bellis et al $(2016,2017)$. The model is based on an explicit kinematic description of rock behaviour by means of connected patterns of parallel equi-spaced faults that exist at the material level: this micro-mechanical description guarantees that the rock undergoes compatible deformations and remains in static equilibrium down to the micro-mechanical level. Each family of faults is characterized by a spacing $L$ and a unit normal $\mathbf{N}$ to the plane of the faults. In the following, for the sake simplicity, it is assumed that just one family of fault can develop in the material. The deformation of the rock is due to the contribution of both the deforming homogenous rock matrix, $\varepsilon^{m}$, and the opening faults, $\varepsilon^{f}$, according to:

$$
\varepsilon=\varepsilon^{m}+\varepsilon^{f}=\varepsilon^{m}+\frac{1}{2 L}(\boldsymbol{\Delta} \otimes \mathbf{N}+\mathbf{N} \otimes \boldsymbol{\Delta})
$$

being $\boldsymbol{\Delta}$ the displacement jump of the faults (i.e. the relative displacement of the two sides of the fault) and $\otimes$ the dyadic product.

Remarkably, the fracture pattern predicted by the model follows from a thermodynamically consistent approach. Fault inception, orientation and spacing are evaluated under the assumption that an incremental work of deformation exits, capable of accounting for both the reversible and dissipative behaviour of the rock. Assuming that the material state at the representative elementary volume level at time $t_{n}$ is known, a numerical solution strategy is 
employed to calculate incrementally the fault pattern and the effective stress at time $t_{n+1}=t_{n}+\Delta t$ for a given total deformation $\varepsilon_{n+1}$. The incremental work of deformation $E_{n}\left(\varepsilon_{n}, \Delta, q\right)$ over the time interval $\Delta t$ is defined as the sum of elastic, cohesive and frictional contributions:

$$
E_{n}\left(\varepsilon_{n}, \boldsymbol{\Delta}, q\right)=W^{m}\left(\varepsilon_{m}\right)+\frac{1}{L} \Phi(\boldsymbol{\Delta}, q)+\frac{\Delta t}{L} \psi^{*}\left(\frac{\boldsymbol{\Delta}-\boldsymbol{\Delta}_{n}}{\Delta t}, \boldsymbol{\varepsilon}, \boldsymbol{\Delta}\right),
$$

where $W^{m}$ is the elastic strain energy density per unit volume of the matrix, $\Phi$ is the cohesive energy density per unit surface of the faults, the term including $\psi^{*}$ represent the frictional dissipation in $\Delta t$ and $q$ is an internal variable describing the state of the faults. The cohesive energy $\Phi(\boldsymbol{\Delta}, q)$ has been defined assuming a linear decreasing cohesive law, according to De Bellis et al (2016, 2017). Just two parameters are thus needed to describe the cohesive behaviour: the tensile strength $S_{T}$ and the critical energy release rate $G_{c}$. The tensile strength $S_{T}$ corresponds to the maximum attainable effective traction on the faults, while $G_{c}$ is the area enclosed by the cohesive law. According to standard cohesive theory, a critical opening displacement $\Delta_{c}=2 G_{c} / S_{T}$ can be defined: for opening larger than the critical one, cohesive forces vanishes. Irreversibility is introduced in the damage law by means of the scalar internal variable $q$, corresponding to the maximum opening attained by the fault. Upon unloading, the cohesive behaviour of the fault is supposed to be linear elastic up the origin. Frictional dissipation processes are finally accounted for via the introduction of a dual dissipation potential per unit fault area $\psi^{*}$. According to the Coulomb friction model, it reads:

$$
\psi^{*}=\mu \max \left\{0,\left(\boldsymbol{\sigma}^{\prime} \mathbf{N}\right) \cdot \mathbf{N}\right\}|\dot{\boldsymbol{\Delta}}|,
$$

where $\mu=\tan \left(\phi^{\prime}\right)$ is the friction coefficient, $\left(\boldsymbol{\sigma}^{\prime} \mathbf{N}\right) \cdot \mathbf{N}$ is normal component of the traction vector on fault plane and $|\dot{\boldsymbol{\Delta}}|$ the norm of the displacement jump rate. The model thus accounts for two types of material failure: in tension (according to the Galileo-Rankine criterion) and in shear (according to the Mohr-Coulomb criterion). The solution of the incremental problem is obtained by the minimization of the incremental work of deformation, subjected to the constrains provided by the impenetrability of the closed faults (i.e. $\Delta_{N} \geq 0$ ) and the irreversibility of damage (i.e. $\Delta q \geq 0$ ). The minimization process finally provides the solution in terms of fault spacing and orientation: further details on the model equations and the numerical solution strategy can be found in De Bellis et al. (2016). From the practical point of view, just 6 material parameters are needed:

- The Young modulus $E$ and the Poisson ratio $\nu$, describing the elastic behaviour of the homogeneous matrix, i.e. the behaviour of the material in the pre-failure stage;

- The friction angle $\phi^{\prime}$ and the tensile strength $S_{T}$, describing the failure properties of the rock according to the Mohr-Coulomb failure criterion;

- The critical energy release rate $G_{c}$; 
- A scale parameter $L_{0} / \Delta_{c}$.

The model proved able to reproduce the triaxial response of different type of rock, both in the pre- and post-peak stages, as shown in De Bellis et al $(2016,2017)$ and Della Vecchia et al (2016).

In the context of the determination of the in-situ stress state, numerical simulations with the advanced model have been performed with the aim of providing a validation of the simplified analytical model presented in Step 4. The excavation of a vertical borehole within a horizontally bedded rock formation has been simulated via the Finite Element method, starting from a computational domain that includes a $1 \mathrm{~m}$ thick, $40 \mathrm{~m}$ wide horizontal square layer perpendicular to the borehole axis. The finite element mesh consists of 8,010 nodes and 36,086 tetrahedral elements. The simulation of the excavation is achieved numerically by removing (or deactivating) the elements that fall at the interior of a cylindrical cavity, whose radius takes the value $a=1$ $\mathrm{m}$. The model is able to predict the evolution of stress concentration around the borehole, together with the development of shear-induced failures, in correspondence to the maximum deviatoric stress, and tensile fractures. In the context of this paper, Figure 8 shows the elements (red spheres) characterized by the presence of shear induced fractures for two different stress anisotropy ratios $S_{H}^{\prime} / S_{h}^{\prime}$, equal to 4.0 and 4.5 , for the Chelungpu example. The material parameters used are listed in Table 3. As expected, the higher the anisotropy ratio in the horizontal plane, the larger the amplitude of the failed zone. By a visual evaluation of the amplitude of the failed zone, the relationship between $\theta_{b}$ and $S_{H}^{\prime}$ can be estimated, according to the advanced constitutive model proposed. It is worth noting that, due to the stress redistribution induced by the failed elements, the numerical model has the built-in capability in accounting for the variation in borehole shape (i.e. ovalization) induce by breakout failures.

\begin{tabular}{cccccc}
\hline$E$ & $\nu$ & $\mu$ & $S_{T}$ & $G_{c}$ & $L_{0} / \Delta_{c}$ \\
{$[\mathrm{kPa}]$} & {$[-]$} & {$[-]$} & {$[\mathrm{kPa}]$} & {$[\mathrm{kN} / \mathrm{m}]$} & {$[-]$} \\
\hline $13.7 \cdot 10^{9}$ & 0.35 & 0.7 & 29,800 & 0.005 & 1
\end{tabular}

Table 3 Material parameters introduced in the numerical simulations for Chelungpu-B

Simulations have been carried out by varying the value of $S_{H}^{\prime}$ at a constant $S_{h}^{\prime}$, measuring the resulting breakout amplitude, if any. Results of the simulation in terms of breakout amplitude for different $S_{H}^{\prime}$ values are indicated with black points in Figure 9 for the Chelungpu site, while the continuous line represents the outcome of the simplified analytical procedure (Equation 20). Despite the strong assumptions at the basis of the analytical procedure, the accordance between the two prediction is remarkably good, at least for breakout amplitudes not exceeding $90^{\circ}$. It is worth noting that, for parameter 


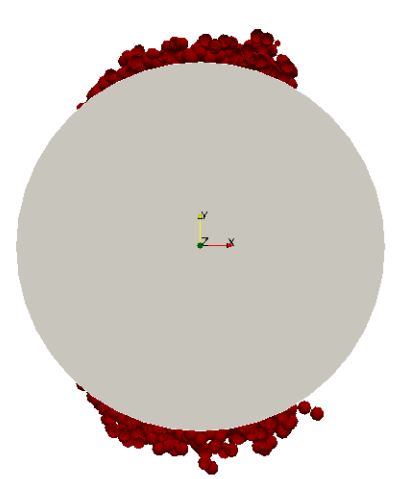

(a) $S_{H}^{\prime} / S_{h}^{\prime}=4.0$

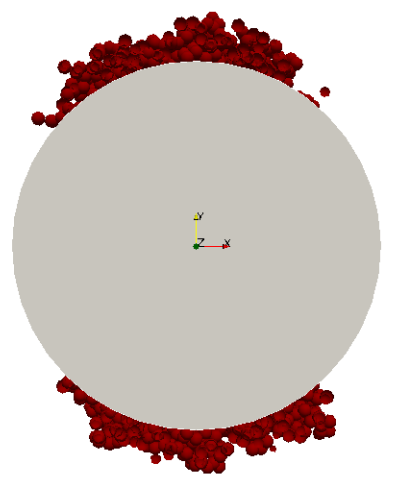

(b) $S_{H}^{\prime} / S_{h}^{\prime}=4.5$

Fig. 8 Evolution of the zones subjected to shear failures at varying far-field stress anisotropies

calibration, real data coming from the relevant literature have been used: however, available information is generally limited to friction angle and uniaxial compressive strength, which can be related to the tensile strength according to the Mohr-Coulomb failure criterion. As for the elastic parameters, $E$ and $\nu$, typical values for any kind of rock can be easily found in the literature. The remaining parameters are more complex to determine: in order to avoid to consider them as variables that can be used a posteriori to fit the analytical equation, sensitivity analyses have been performed in order to highlight their role for the problem at hand: as shown in Scelsi (2017), the evolution of $\theta_{b}$ with the far-field stress is not significantly influenced by $G_{c}$ and $L_{0} / \Delta_{c}$. Values of these parameters have just been taken from the literature (e.g. De Bellis et al. (2016, 2017), Della Vecchia et al. (2016)), without any significant influence on the numerical validation.

\section{Experimental and numerical validation of case histories from the literature}

In this section, a further numerical and experimental validation of the proposed simplified procedure is presented, basing on two case histories presented in the literature.

\subsection{Basel 1 enhanced geothermal system}

In 2006 a 5-km-deep borehole has been drilled under the Swiss city of Basel with the aim of developing an "Enhanced Geothermal System" EGS for a geothermal power plant. The orientation of the maximum horizontal principal stress has been determined from the observations of failures derived from ultrasonic televiewer images in 2 two vertical boreholes. In the granite, tensile 


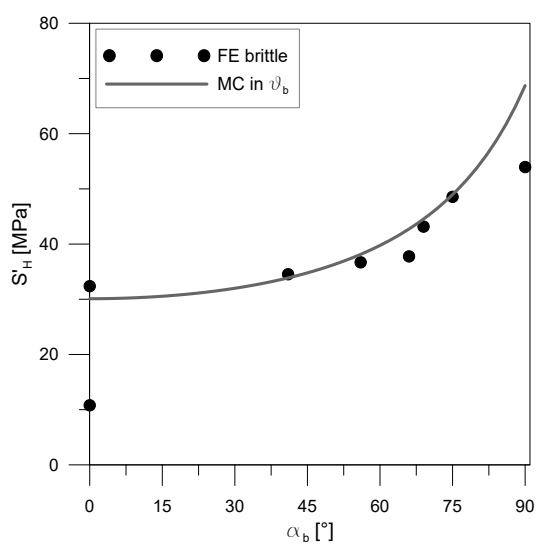

Fig. 9 Chelungpu, Hole-B (1000 $\mathrm{m}$ depth); comparison between the simplified analytical model and numerical results.

fractures are present in intermittent way, while breakout are present almost continually, except for the first $100 \mathrm{~m}$ where they are sparse. The mean orientation of $S_{H}$ from tensile and breakout failures is $\mathrm{N} 143^{\circ} \mathrm{E} \pm 14^{\circ}$. Information about material properties and in situ stress state can be found in different studies presented in the literature (e.g. Valley and Evans, 2015, Haring et al., 2008). The profile of the breakout width is also available along the whole depth of borehole Basel-1. In the following, the stress state at $4,632 \mathrm{~m}$ will be analysed, where the measurement of $S_{h}$ is available $\left(S_{h}^{\prime}=74.4 \mathrm{MPa}\right)$. Rock properties and the known effective stress state, taken from Valley \& Evans (2015), are listed in Table 4.

\begin{tabular}{lc}
\hline Property & Value \\
\hline$S_{v}^{\prime}[\mathrm{MPa}]$ & 69.6 \\
$S_{h}^{\prime}[\mathrm{MPa}]$ & 28.9 \\
$\phi^{\prime}\left[{ }^{\circ}\right]$ & 44 \\
$\mathrm{C}[\mathrm{MPa}]$ & 167 \\
$\theta_{b}\left[^{\circ}\right]$ & $\approx 60$ \\
\hline
\end{tabular}

Table 4 Data used in the study of Basel-1 at $4.632 \mathrm{~km}$ depth (Valley \& Evans, 2015).

The analytical procedure have been applied according to the following steps:

- Step 1: limits on the stress state from the tectonic regime

The polygon of the admissible stress states in the plane $S_{H}^{\prime}-S_{h}^{\prime}$ is represented considering all faulting regimes. Figure 10(a) allows to identify graphically the first limits on $S_{H}^{\prime}$ : this value has to be between $S_{h}^{\prime}=28.96$ $\mathrm{MPa}$ by definition and $160.73 \mathrm{MPa}\left(S_{H}^{\prime} / S_{h}^{\prime}=5.6\right)$, i.e. limit deriving from 


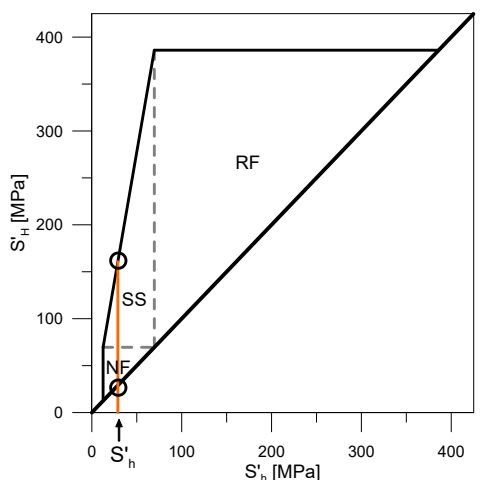

(a)

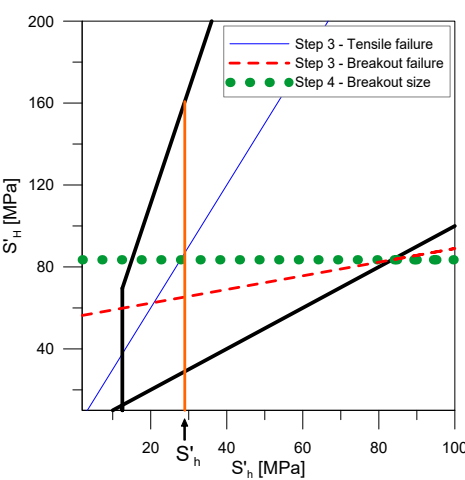

(b)

Fig. 10 (a) Admissible stress polygon. (b) Lines dividing stresses associated to different type of failures. The blue thin solid line represents tensile fractures, red dashed line the shear failures in $\theta=\pi / 2$. The green dotted line indicates the value of $S_{H}^{\prime}$ at $\theta_{b}=60^{\circ}$, according to Eq. 20.

strike-slip regime. From the polygon it can be easily deduced that the tectonic regime can be either normal or strike-slip.

Step 2: limits on the stress state from failure orientation Principal stresses are computed using the relation defined by Equations (8) $\theta=0$ and from Eq. (10) at $\theta=\pi / 2$. The components corresponding to

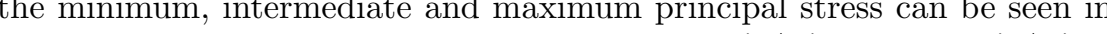
Figure 11 for admissible tensional anisotropies $S_{H}^{\prime} / S_{h}^{\prime}$, i.e. $1 \leq S_{H}^{\prime} / S_{h}^{\prime} \leq$ 6. It can be observed that: anisotropies $S_{H}^{\prime} / S_{h}^{\prime}<1.2$ for which the vertical stress is greater than the hoop stress. The presence of visual observations of failure directions could thus allow a further refinement of $S_{H}^{\prime}$ bounds;

- in $\theta=0$, since no tensile fractures are registered at the considered depth, the relation between stress components cannot be used to further limit the anisotropy $S_{H}^{\prime} / S_{h}^{\prime}$.

- Step 3: limits on the stress state from rock failure criterion

Breakout failures have been registered in the section taken into account, while tensile fractures are absent. The Mohr-Coulomb failure criterion with tension cut-off is assumed to hold $\left(\phi^{\prime}=44^{\circ}, C=167 \mathrm{MPa}, S_{T}=0 \mathrm{MPa}\right)$. The lines delimiting the presence or absence of fractures are drawn in the stress polygon (Figure 10(b)); the stress state has to lie below the line representing tensile fractures, and above the line delimiting breakout failures.

Considering the absence of tensile fractures, it can be stated that $S_{H}^{\prime}$ has to be smaller than $86.88 \mathrm{MPa}$; for shear failures in $\theta=\pi / 2 S_{H}^{\prime}>65.32 \mathrm{MPa}$. Therefore $2.3<S_{H}^{\prime} / S_{h}^{\prime}<3.0$. 


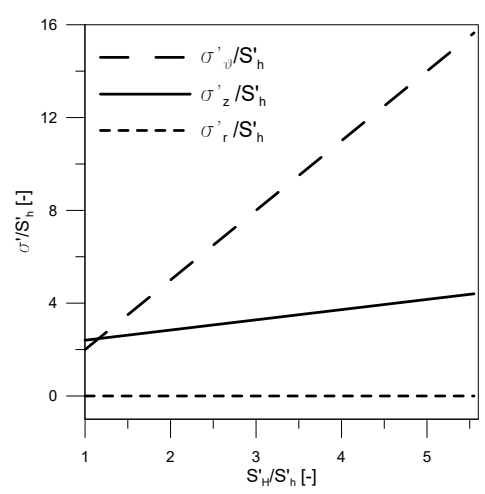

(a) $\theta=\pi / 2$

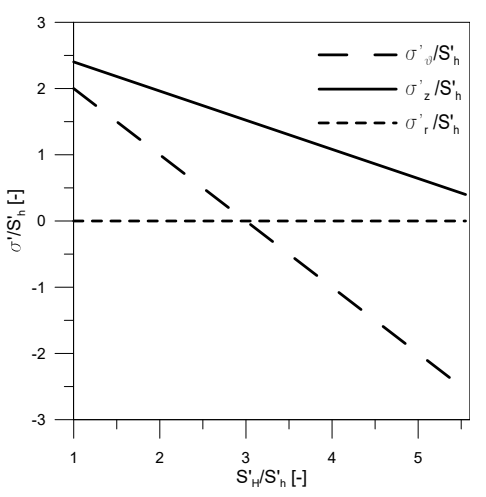

(b) $\theta=0$

Fig. 11 Visualization of the relation between normalized principal components as a function of $S_{H}^{\prime} / S_{h}^{\prime}$, limited between admissible values derived by tectonic limits; $\nu=0.22, p_{\text {net }}=0$.

- Step 4: accounting for breakout size

Being the breakout angle approximately known $\left(\theta_{b} \approx 60^{\circ}\right.$, corresponding to an amplitude $\alpha_{b} \approx 60^{\circ}$ ), a single value of the maximum horizontal farfield stress state can be determined. According to eq. $20, S_{H}^{\prime} \simeq 83.50 \mathrm{MPa}$ (corresponding to $S_{H}^{\prime} / S_{h}^{\prime}=2.9$ ) and thus $S_{H}=128.94 \mathrm{MPa}$. This value falls between the limits obtained in Step 3.

The tectonic regime is strike-slip, as it is clearly shown in Figure 10(b). The maximum horizontal stress $\left(S_{H}=128.94 \mathrm{MPa}\right)$ differs of about $10 \mathrm{MPa}$ from the value estimated by Valley \& Evans (2015) with their empirical interpolation $S_{H}=1.04 z+115 \mathrm{MPa} / \mathrm{km}$, which gives a result equal to $119.82 \mathrm{MPa}$

\begin{tabular}{cccl}
\hline Step & $S_{H}^{\prime \min }[\mathrm{MPa}]$ & $S_{H}^{\prime \max }[\mathrm{MPa}]$ & Information needed \\
\hline 1 & 28.96 & 160.73 & Broad estimate of $\phi^{\prime}$ \\
2 & Data not available & Data not available & Visual information of failures \\
3 & 65.32 & 86.88 & $C, \phi^{\prime}, S_{T}$ \\
4 & 83.50 & 83.50 & $C, \phi^{\prime}$, breakout width \\
\hline
\end{tabular}

Table 5 Bounds for $S_{H}^{\prime}$ for each step using the proposed procedure for Basel-1 at $4632 \mathrm{~m}$

Table 5 summarises the bounds for $S_{H}^{\prime}$ for each step of the proposed approach for the Basel-1 borehole at $4632 \mathrm{~m}$.

The maximum horizontal stress obtained via the analytical procedure has been also validated by means of the numerical model described in Section 3. Material parameters are listed in Table 6 , while the principal stress components $S_{v}^{\prime}$ and $S_{h}^{\prime}$ and the breakout width have been introduced in Table 4 . 


\begin{tabular}{cccccc}
\hline$E$ & $\nu$ & $\mu$ & $S_{T}$ & $G_{c}$ & $L_{0} / \Delta_{c}$ \\
{$[\mathrm{kPa}]$} & {$[-]$} & {$[-]$} & {$[\mathrm{kPa}]$} & {$[\mathrm{kN} / \mathrm{m}]$} & {$[-]$} \\
\hline $65 \cdot 10^{6}$ & 0.22 & 0.97 & 36700 & 0.005 & 1
\end{tabular}

Table 6 Material parameters introduced in the numerical simulations for Basel-1.

Different simulations have been carried out by varying $S_{H}^{\prime}$ between $29 \mathrm{MPa}$ (corresponding to $S_{H}^{\prime} / S_{h}^{\prime}=1$ ) and $159 \mathrm{MPa}$ (corresponding to $S_{H}^{\prime} / S_{h}^{\prime}=5.5$ ), measuring for each simulation the predicted breakout width. The obtained results are plotted in Figure 12, together with the $S_{H}^{\prime}$ trend obtained at Step 4 via eq. 20. The numerical and analytical predictions are substantially essentially coincident up to an anisotropy ratio $S_{H}^{\prime} / S_{h}^{\prime}=4$ equal to 4 and to a width $\alpha_{b} \approx 90^{\circ}$, the maximum relative error being lower than $15 \%$.

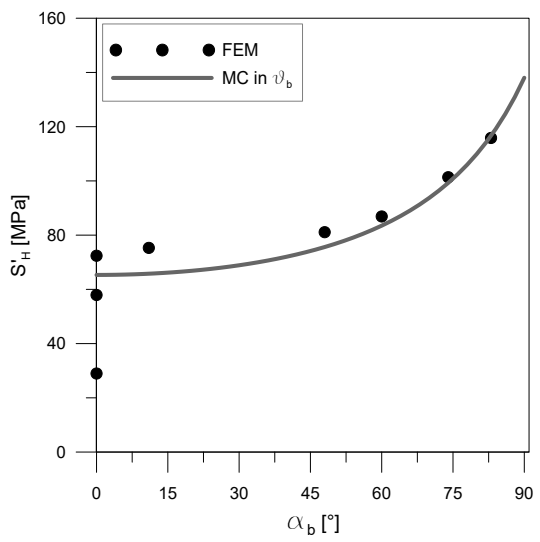

Fig. 12 Basel-1; evaluation of $S_{H}^{\prime}$ through the Mohr-Coulomb failure criterion imposition in $\theta=\theta_{b}$ and results of simulations with brittle damage model.

\subsection{Cajon Pass Scientific Research Borehole}

At the Cajon Pass site (California) a scientific research borehole was conducted between 1986 and 1987, reaching a depth of $3500 \mathrm{~m}$. In the literature several publications (Zoback \& Healy (1992), Vernik \& Nur (1992), Vernik \& Zoback (1992)) provide information regarding the material characteristics and the in situ stress state; some minimum horizontal principal stress $S_{h}$ measurements and the amplitude of the breakout for depths between $907 \mathrm{~m}$ and $3486 \mathrm{~m}$ have been obtained respectively via hydraulic fracturing and borehole televiewer. In this case a depth of $2048 \mathrm{~m}$ has been considered, where an estimate of the maximum horizontal stress $S_{H}$ is available in Zoback \& Healy (1992). Rock properties and the known stress state are listed in Table 7. 


\begin{tabular}{lc}
\hline Property & Value \\
\hline$S_{v}^{\prime}[\mathrm{MPa}]$ & 32.15 \\
$S_{h}^{\prime}[\mathrm{MPa}]$ & 19.81 \\
$\phi^{\prime}\left[{ }^{\circ}\right]$ & 39 \\
$\mathrm{C}[\mathrm{MPa}]$ & 132 \\
$T_{0}[\mathrm{MPa}]$ & 13 \\
$\theta_{b}\left[^{\circ}\right]$ & $\approx 73$ \\
\hline
\end{tabular}

Table 7 Data used in the study of Cajon Pass at $2.048 \mathrm{~km}$ depth.

The analytical procedure was applied according to the following steps:

- Step 1: limits on the stress state from the tectonic regime

The polygon of the admissible stress states in the plane $S_{H}^{\prime}-S_{h}^{\prime}$ is represented considering all faulting regimes. Figure 13(a) allows the graphical identification of the first limits on $S_{H}^{\prime}$ : this value has to be between $S_{h}^{\prime}=19.81 \mathrm{MPa}$ by definition and $85.75 \mathrm{MPa}\left(S_{H}^{\prime} / S_{h}^{\prime}=4.3\right)$, i.e. limit deriving from strike-slip regime. From the polygon it can be deduced that the tectonic regime can be either normal or strike-slip.

- Step 2: limits on the stress state from failure orientation Principal stresses are computed using the relation defined by Equations (8) for $\theta=0$ and from Eq. (10) at $\theta=\pi / 2$. The components corresponding to the minimum, intermediate and maximum principal stress can be seen in Figure 14 for admissible tensional anisotropies $S_{H}^{\prime} / S_{h}^{\prime}$, i.e. $1 \leq S_{H}^{\prime} / S_{h}^{\prime} \leq$ 4.3. It can be observed that:

- $\sigma_{r}^{\prime}<\sigma_{z}^{\prime}<\sigma_{\theta}^{\prime}$ in $\theta=\pi / 2$ for all the values of $S_{H}^{\prime} / S_{h}^{\prime}$. The presence of visual observations of failure directions could thus allow a further refinement of $S_{H}^{\prime}$ bounds.

- in $\theta=0$, since no tensile fractures are registered at the considered depth, the relation between stress components cannot be used to further limit the anisotropy $S_{H}^{\prime} / S_{h}^{\prime}$.

- Step 3: limits on the stress state from rock failure criterion

Breakout failures have been registered in the section taken into account, while tensile fractures are absent. The Mohr-Coulomb failure criterion with tension cut-off is assumed to hold $\left(\phi^{\prime}=39^{\circ}, C=132 \mathrm{MPa}, S_{T}=0 \mathrm{MPa}\right)$. The lines delimiting the presence or absence of fractures are inserted in the stress polygon (Figure 13(b)); the stress state has to lie below the line representing tensile fractures, and above the line delimiting breakout failures.

Considering the absence of tensile fractures, it can be stated that $S_{H}^{\prime}$ has to be smaller than $72.43 \mathrm{MPa}$; for shear failures in $\theta=\pi / 2 S_{H}^{\prime}>50.60 \mathrm{MPa}$. Therefore $2.6<S_{H}^{\prime} / S_{h}^{\prime}<3.7$.

- Step 4: accounting for breakout size 


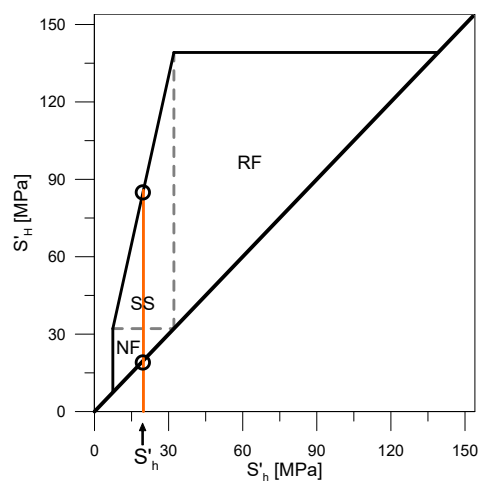

(a)

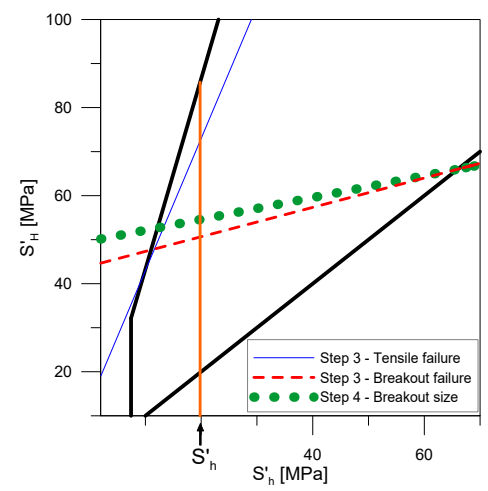

(b)

Fig. 13 (a) Admissible stress polygon. (b) Lines dividing stresses associated to different type of failures. The blue thin solid line represents tensile fractures, red dashed line the shear failures in $\theta=\pi / 2$. The green dotted line indicates the value of $S_{H}^{\prime}$ at $\theta_{b}=73^{\circ}$, according to Eq. 20.

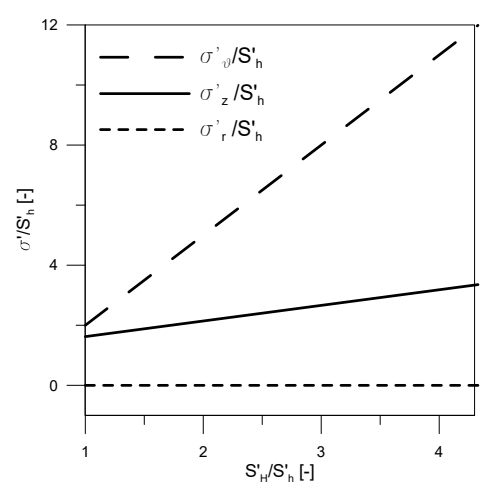

(a) $\theta=\pi / 2$

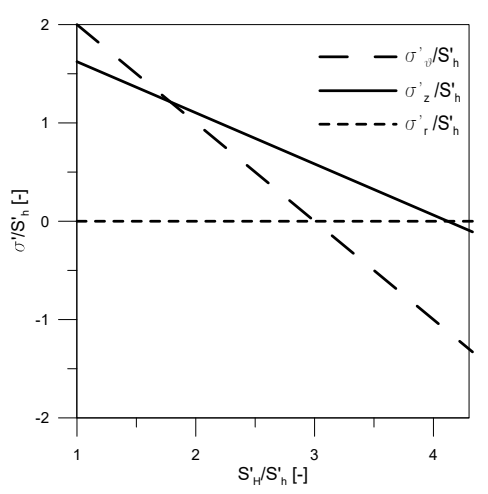

(b) $\theta=0$

Fig. 14 Visualization of the relation between normalized principal components as a function of $S_{H}^{\prime} / S_{h}^{\prime}$, limited between admissible values derived by tectonic limits; $\nu=0.26, p_{\text {net }}=0$.

Being the breakout angle approximately known $\left(\theta_{b} \approx 73^{\circ}\right.$, corresponding to an amplitude $\alpha_{b} \approx 34^{\circ}$ ), a single value of the maximum horizontal farfield stress state can be determined. According to eq. $20, S_{H}^{\prime} \simeq 54.56 \mathrm{MPa}$ (corresponding to $S_{H}^{\prime} / S_{h}^{\prime}=2.8$ ) and thus $S_{H}=74.7 \mathrm{MPa}$. This value falls between the limits obtained in Step 3.

The tectonic regime is strike-slip, as it is clearly shown in Figure 13(b). The maximum horizontal stress $\left(S_{H}=74.7 \mathrm{MPa}\right)$ differs of only $4.6 \mathrm{MPa}$ from the value estimated from hydraulic fracturing data, equal to $79.3 \mathrm{MPa}$, reported in Zoback \& Healy (1992).

Table 5 summarises the bounds for $S_{H}^{\prime}$ for each step of the proposed approach for the Cajon Pass Borehole at $2048 \mathrm{~m}$. 


\begin{tabular}{cccl}
\hline Step & $S_{H}^{\prime}{ }^{\min }[\mathrm{MPa}]$ & $S_{H}^{\prime \max }[\mathrm{MPa}]$ & Information needed \\
\hline 1 & 19.81 & 85.75 & Broad estimate of $\phi^{\prime}$ \\
2 & Data not available & Data not available & Visual information of failures \\
3 & 50.60 & 72.43 & $C, \phi^{\prime}, S_{T}$ \\
4 & 54.56 & 54.56 & $C, \phi^{\prime}$, breakout width \\
\hline
\end{tabular}

Table 8 Bounds for $S_{H}^{\prime}$ for each step using the proposed procedure for Cajon Pass Borehole at $2048 \mathrm{~m}$

Material parameters are listed in Table 9, while the principal stress components $S_{v}^{\prime}$ and $S_{h}^{\prime}$ and the breakout width have been introduced in Table 7.

\begin{tabular}{cccccc}
\hline$E$ & $\nu$ & $\mu$ & $S_{T}$ & $G_{c}$ & $L_{0} / \Delta_{c}$ \\
{$[\mathrm{kPa}]$} & {$[-]$} & {$[-]$} & {$[\mathrm{kPa}]$} & {$[\mathrm{kN} / \mathrm{m}]$} & {$[-]$} \\
\hline $90 \cdot 10^{6}$ & 0.26 & 0.8 & 39700 & 0.005 & 1 \\
\hline
\end{tabular}

Table 9 Material parameters introduced in the numerical simulations for Cajon Pass Borehole at $2048 \mathrm{~m}$ depth.

Different simulations have been carried out by varying $S_{H}^{\prime}$ between $20 \mathrm{MPa}$ (corresponding to $S_{H}^{\prime} / S_{h}^{\prime}=1$ ) and $109 \mathrm{MPa}$ (corresponding to $S_{H}^{\prime} / S_{h}^{\prime}=5.5$ ), measuring for each simulation the predicted breakout width. The obtained results are plotted in Figure 15, where a comparison with the $S_{H}^{\prime}$ trend, obtained via eq. 20, is shown.

Also in this case the numerical and analytical predictions are essentially coincident up to an anisotropy equal to 4 and to a width $\alpha_{b} \approx 90^{\circ}$, being the maximum relative error lower than $3.5 \%$.

\section{Conclusion}

Determination of in situ stress state is a preliminary activity necessary for any application in the field of civil and reservoir engineering, as well as for geological and geophysical applications. Among the different techniques proposed in the literature to estimate in situ stress state in rock masses, borehole methods are certainly the most diffused. For these methods to be reliable, a sound geomechnical model is needed, in order to address all the relevant characteristics of rock mechanical response that influence the behaviour of the material at the borehole scale. Unfortunately, refined models always requires a significant number of parameters, which can hardly be known without a dedicated, time consuming and expensive laboratory activity. In order to overcome such limitations, this paper presented an analytical procedure to estimate in situ stress state trying to combine a rigorous approach to the applicability of the 


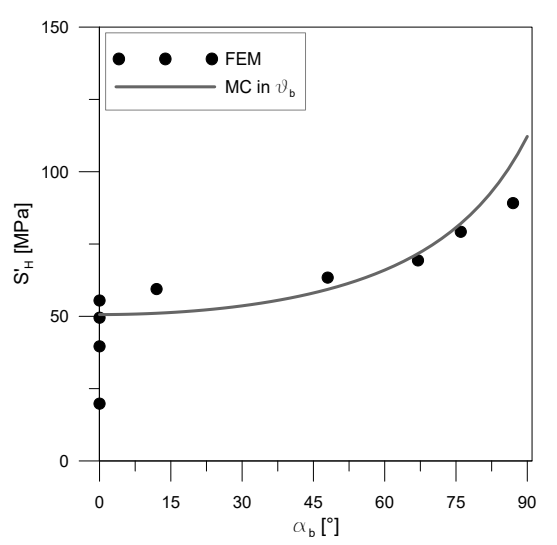

Fig. 15 Cajon Pass; evaluation of $S_{H}^{\prime}$ through the Mohr-Coulomb failure criterion imposition in $\theta=\theta_{b}$ and results of simulations with brittle damage model.

procedure in engineering practice. In particular, the procedure is intented to be applied following some clear steps, each one requiring some input parameters and proving some bounds to the maximum horizontal stress, i.e. the most difficult stress component to determine. Step 1 stems from the application of the well-known Anderson faulting theory together with the Mohr-Coulomb failure criterion to provide some initial bounds to the stress state, exploing information known at the reservoir scale, as already proposed in the literature. A refinement on in situ stress bounds is provided by Step 2, that just relies on visual information on failures at the borehole scale. In Authors' knowledge, this approach has never been proposed in the literature, and provides a significant reduction in stress bounds without the need of knowing rock failure parameters. Further refinement is provided by Step 3, which combine the information of the possible presence of failures at the borehole scale with the information on the failure criterion of the rock. Finally, if also breakout failure amplitude is available, a unique value of the maximum horizontal stress can be estimated via Step 4. Remarkably, just three parameters to describe rock strength have been introduced: the friction angle, the uniaxial strength and the tensile resistance. As a further advantage of the procedure, no programming or use of dedicated software is need: once the input data are known, just explicit algebric equations are proposed.

The procedure has been then validated by means of both numerical analyses and some field data coming from the literature. Numerical analyses have been performed to check if the simplifications introduced in Step 4, involving both the mechanical behaviour of the rock and the geometry of the failed borehole, are relevant. To this aim, numerical Finite Element analyses at the borehole scale have been performed, assuming a brittle damage behaviour of the rock. The constitutive model adopted in the simulations is able to well reproduce the behavior of different rocks under different stress levels, and in particular the expected post-peak brittle response. The model, based on 
micro-mechanical considerations and on strong thermodynamical bases, provides predictions that can be considered consistent with softening/hardening elasto-plasticity, yet in a framework more consistent with the failure processes in rocks. The outcomes of the numerical simulations have been compared with the Equations proposed in Step 4 in terms of borehole breakout dependence on stress anisotropy: the agreement between the two approaches is very good, at least for breakount amplitude lower than $90^{\circ}$, confirming that the assumption on which Step 4 relies are acceptable for the problem at hand. Finally, reasonable agreement has been obtained also between the predictions of the procedure with some data already present in the literature, where in situ stress estimate was performed by means of the combination of different techniques.

\section{References}

1. Aadnoy, B.S., In-situ stress directions from borehole fracture traces, Journal of Petroleum Science and Engineering, 4, 143-153 (1990)

2. Aadnoy, B.S., Kaarstad, E., de Castro Goncalves, C.J., Obtaining both horizontal stresses from wellbore collapse, In: SPE/IADC Drilling Conference and Exhibition, IADC/SPE 163563, 1-12 (2013)

3. Amadei B. and Stephansson O., Rock Stress and Its Measurements, Chapman \& Hall, London (1997)

4. Barton C. A., Castillo D. A., Moos D., Peska P. and Zoback M., Characterising the full stress tensor based on observations of drilling-induced wellbore failures in vertical and inclined boreholes leading to improved wellbore stability and permeability prediction, APPEA Journal, 38, 466-487 (1998)

5. Barton C.A., Zoback M.D., Burns K.L., In-situ stress orientation and magnitude at the Fenton geothermal site, New Mexico, determined from wellbore breakouts, Geophysical Research Letters, 1988

6. Bell J., Practical methods for estimating in situ stress for borehole stability applications in sedimentary basins, Journal of Petroleum Science and Engineering, 38, 111-119 (2003)

7. Bell J.S., Gough D.I., Northeast-southwest compressive stress in Alberta: evidence from oil wells, Earth and Planetary Science Letters, 45 (2) 475-482 (1979)

8. De Bellis M.L., Della Vecchia G., Ortiz M., Pandolfi A., A linearized porous brittle damage material model with distributed frictional-cohesive faults, Engineering Geology, 215, 10-24 (2016)

9. De Bellis M.L., Della Vecchia G., Ortiz M., Pandolfi A., A multiscale model of distributed fracture and permeability in solids in all-round compression, Journal of the Mechanics and Physics of Solids, 104, 12-31, ISSN 0022-5096 (2017)

10. Della Vecchia G., De Bellis M.L., Pandolfi A., A multiscale microstructural model of damage and permeability in fractured solids. Procedia Engineering 158, 21-26 (2016)

11. Della Vecchia G., Pandolfi A., Musso G., Capasso G., An analytical expression for the determination of in situ stress state from borehole data accounting for breakout size, International Journal of Rock Mechanics \& Mining Sciences 66, 64-68 (2014)

12. Espinoza D. N., Pereira J. M., Vandamme M., Dangla P., Vidal-Gilbert S., Desorptioninduced shear failure of coal bed seams during gas depletion, International Journal of Coal Geology, 137, 142-151 (2015)

13. Gueguen Y. and Bouteca M., Mechanical properties of rocks: pore pressure and scale effects, Oil \& Gas Science and Technology, 54(6), 703-714 (1999)

14. Haimson B., Lin W., Oku H., Hung J.H., Song S.R., Integrating borehole-breakout dimensions, strength criteria, and leak-off test results, to constrain the state of stress across the Chelungpu Fault, Taiwan, Tectonophysics, 482, 65-72 (2009)

15. Haimson B. and Rudnicki J.W., The effect of the intermediate principal stress on fault formation and fault angle in siltstone, Journal of Structural Geology, 32, 1701-1711 (2009) 
16. Han B., Shen W.Q., Xie S.Y., Shao J.F., Influence of pore pressure on plastic deformation and strength of limestone under compressive stress, Acta Geotechnica, 1-11 (2018)

17. Häring M. O., Schanz U., Ladner F., Dyer B. C., Characterisation of the Basel 1 enhanced geothermal system, Geothermics, 37, 469-497(2008)

18. Hashemi S. S., Taheri A., Melkoumian N., Shear failure analysis of a shallow depth unsupported borehole drilled through poorly cemented granular rock, Engineering Geology, 183, 39-52 (2014)

19. Hashemi S. S., Taheri A., Melkoumian N., An experimental study on the relationship between localised zones and borehole instability in poorly cemented sand, Journal of Petroleum Science and Engineering, 135, 101-117 (2015)

20. Hung J. H., Ma K. F., Wang C. Y., Ito H., Lin W., Yeh E. C., Subsurface structure, physical properties, fault-zone characteristics and stress state in scientific drill holes of Taiwan Chelungpu Fault Drilling Project, Tectonophysics, 466, 307-321 (2007)

21. Jaeger J., Cook N.and Zimmermann R., Fundamental of Rock Mechanics, Blackwell Publishing, Oxford (2007)

22. Jaky J., The coefficient of earth pressure at rest, Journal of Society of Hungarian Architects and Engineers, 78 (22) 355-358 (1944)

23. Leeman E., The measurement of stress in rock, Parts I, II and III. Journal of the Southern African Institute of Mining and Metallurgy, 65:45-114, 254-284 (1964)

24. Lin W., Yeh E. C., Hung J. H., Haimson B., Hirono T., Localized rotation of principal stress around faults and fractures determined from borehole breakouts in hole B of the Taiwan Chelungpu-Fault Drilling Project (TCDP), Tectonophysics, 482, 82-91 (2009)

25. Moos D. and Zoback M.D., Utilization of observations of well bore failure to constrain the orientation and magnitude of crustal stresses: application to continental deep sea drilling project and ocean drilling program boreholes, Journal of Geophysical Research, 95, 9305-25 (1990)

26. Onaisi A., Sarda J.P. and Bouteca M., Experimental and theoretical investigation of borehole breakouts, in Proc. 31st US Symp. Rock Mech., Golden, Balkema, Rotterdam, 703-710 (1990).

27. Scelsi G., Determinazione dello stato di sforzo in situ a partire da dati di scavo di pozzo, MSc Thesis, Politecnico di Milano (2017)

28. Schmidt B., Discussion paper. Earth pressure at rest related to stress history, Canadian Geotechnical Journal, 3 (4) 239-242 (1966)

29. Sulem J. and Ouffroukh H., Hydromechanical behaviour of Fontainebleau sandstone, Rock Mechanics and Rock Engineering, 39(3), 185 (2006)

30. Valley B., Evans K.F., Estimation of the Stress Magnitudes in Basel Enhanced Geothermal System. Proceedings World Geothermal Congress, Melbourne, Australia, 19-25 April 2015 (2015)

31. Vernik L. and Nur A., Petrophysical Analysis of the Cajon Pass Scientific Well: Implications for Fluid Flow and Seismic Studies in the Continental Crust, Journal of Geophysical Research, 97, B4, 5121-5134 (1992)

32. Vernik L. and Zoback M. D., Estimation of maximum horizontal principal stress magnitude from stress-induced well bore breakouts in the Cajon Pass Scientific Research borehole, Journal of Geophysical Research, 97, B4, 5109-5119 (1992)

33. Vincké O., Boutéca M.J., Piau J.M., Fourmaintraux D., Study of the effective stress at failure. In 1st Biot Conference on Poromechanics: Louvain la Neuve, Belgium, Universite Catholique de Louvain, 635-640 (1998).

34. Wang J.H., Thermal and pore fluid pressure history on the Chelungpu fault at a depth of 1111 m during the 1999 Chi-Chi, Taiwan, earthquake, Journal of Geophysical Research, 116, B03302 (2011)

35. Weibols G.A. and N.G.W. Cook, An energy criterion for the strength of rock in polyaxial compression, International Journal of Rock Mechanics \& Mining Sciences, 5, 529-549 (1968)

36. Wiprut D., Zoback M., Constraining the stress tensor in the Visund Field, Norwegian North Sea: Application to wellbore stability and sand production. International Journal of Rock Mechanics \& Mining Sciences, 37, 317-336 (2000).

37. Wu H. Y., Ma K. F., Zoback M., Boness N., Ito H., Hung J. H. and Hickman S., Stress orientations of Taiwan Chelungpu-Fault Drilling Project (TCDP) hole-A as observed from geophysical logs, Geophysical Research Letters, 34 (2007) 
38. Zang A., Stephansson O., Stress Field of the Earth's Crust, London, Springer (2010)

39. Zheng Z., Kemeny J. and Cook N.G.W., Analysis of borehole breakouts, J. geophys. Res., 94, 7171-7182 (1989)

40. Zoback M., Reservoir Geomechanics, Cambridge University Press, Cambridge (2007)

41. Zoback M.D, Barton C.A., Brudy M., Castillo D.A., Finkbeiner T., Grollimund B.R. Moos D.B., Peska P., Ward C.D., Wiprut D.J., Determination of stress orientation and magnitude in deep wells, International Journal of Rock Mechanics and Mining Sciences, 40, 1049-1076 (2003)

42. Zoback M. D., Healy J. H., In Situ Stress Measurements to $3.5 \mathrm{~km}$ Depth in the Cajon Pass Scientific Research Borehole Implications for the Mechanics of Crustal Faulting. Journal of Geophysical Research, 97, 5039-5057 (1992)

43. Zoback M. D., Mastin L. and Barton C., In-situ Stress Measurements In Deep Boreholes Using Hydraulic Fracturing, Wellbore Breakouts, And Stonely Wave Polarization, in Proc. ISRM International Symposium, International Society for Rock Mechanics (1986)

44. Zoback M. D., Moos D., Mastin L. and Anderson R. N., Well-bore breakouts and in situ stress, J. geophys. Res., 90, 5523-5530 (1985) 